Revue d'histoire de l'Amérique française

REYUE D.HISTOIRE DE L'AMÉRIQUE FRANÇAISE

\title{
SOCIÉTÉ HISTORIQUE DE SAINT-BONIFACE, Histoire de Saint-Boniface, tome 1 : À l'ombre des cathédrales. Des origines de la colonie jusqu'en 1870. Saint-Boniface, Les Éditions du Blé, 1991. 335 p. 34,95 \$
}

\section{Raymond Huel}

Volume 46, numéro 2, automne 1992

URI : https://id.erudit.org/iderudit/305089ar

DOI : https://doi.org/10.7202/305089ar

Aller au sommaire du numéro

Éditeur(s)

Institut d'histoire de l'Amérique française

ISSN

0035-2357 (imprimé)

1492-1383 (numérique)

Découvrir la revue

Citer ce compte rendu

Huel, R. (1992). Compte rendu de [SOCIÉTÉ HISTORIQUE DE SAINT-BONIFACE, Histoire de Saint-Boniface, tome 1 : À l'ombre des cathédrales. Des origines de la colonie jusqu'en 1870. Saint-Boniface, Les Éditions du Blé, 1991. 335 p. 34,95 \$]. Revue d'histoire de l'Amérique française, 46(2), 352-354.

https://doi.org/10.7202/305089ar d'utilisation que vous pouvez consulter en ligne. 
SOCIÉTÉ HISTORIQUE DE SAINT-BONIFACE, Histoire de SaintBoniface, tome 1: À l'ombre des cathédrales. Des origines de la colonie jusqu'en 1870. Saint-Boniface, Les Éditions du Blé, 1991.335 p. 34,95\$

Ce livre est le résultat de la recherche de trois historiens dont les travaux ont bénéficié du soutien pécuniaire de la Société historique de SaintBoniface. La juridiction ecclésiastique de Saint-Boniface naquit en 1818 en tant que district du lointain diocèse de Québec; elle prit de l'importance en suivant la vocation ecclésiastique de Saint-Boniface, qui devint vicariat apostolique en 1844, diocèse en 1847 et archidiocèse en 1871. Au début, Saint-Boniface fut l'unique paroisse catholique de la Rivière-Rouge, puis elle fut morcelée et de nouvelles paroisses furent créées pour répondre aux 
exigences démographiques. Ce mouvement de population entraîna de sérieuses conséquences pour Saint-Boniface qui, auparavant, était le plus important centre de population et la «véritable place forte de l'agriculture et de l'élevage». Néanmoins, la ville maintint sa prépondérance grâce à la présence de la cathédrale, à ses institutions et à l'action du clergé. Le sous-titre de ce premier volume, $\dot{A}$ l'ombre des cathédrales, est alors tout à fait pertinent.

Les deux premiers chapitres de l'étude rappellent les divers événements qui sont «indissociablement liés» aux origines de Saint-Boniface. On y retrouve les La Vérendrye à la poursuite de l'illusoire mer de l'Ouest, la concurrence et le conflit entre la Hudson's Bay Company et la North West Company et l'œuvre de colonisation du philanthrope écossais Lord Selkirk. L'union entre traiteurs et autochtones donne naissance à un nouveau groupe social, les Métis, élément nomadique qui vit principalement de la chasse du bison.

Le troisième chapitre traite de l'enracinement de la mission de la Rivière-Rouge en mettant l'accent sur la construction et l'ouverture du palais épiscopal, de l'église, du Collège, de l'École industrielle, et de l'installation des célèbres cloches de Saint-Boniface. Le quatrième chapitre nous décrit la division du groupe catholique en deux éléments: agriculteurs et chasseurs de bisons. Les Métis font partie du groupe majoritaire de chasseurs et la disparition du bison aura de graves conséquences pour leur bien-être et leur place dans la société de la Rivière-Rouge.

Le cinquième chapitre décrit la consolidation des institutions religieuses et ecclésiastiques de Saint-Boniface. Le sixième chapitre établit un bilan de la ville en 1870, au moment où le Canada se prépare à annexer et à administrer l'ancienne Terre de Rupert. Dans la conclusion, Lucien Chaput passe en revue l'ensemble des facteurs internes et externes qui ont influencé le développement de Saint-Boniface et le sort des populations de la région avoisinante. Le rôle dominant de l'Église dans cette période formatrice est mis en évidence et on affirme que dans la période suivante l'archevêché «aura son mot à dire dans la croissance et le rythme de développement du futur centre urbain de Saint-Boniface».

Il y a longtemps qu'on attend une histoire approfondie de cette ville qui a joué un si grand rôle dans l'implantation de la francophonie et du catholicisme dans l'Ouest canadien. Malheureusement, ce volume sera apprécié surtout par les lecteurs qui n'ont pas une connaissance solide de l'histoire de l'Ouest et de l'histoire de l'Église catholique dans cette région. Les autres seront déçus, car malgré quelques renseignements fort intéressants ici et là, ils resteront convaincus de la validité du dicton du philosophe Will Durant: «Rien n'est nouveau sauf l'arrangement.»

Quoi qu'il en soit, cette étude dissipe plusieurs mythes et légendes qui ont cours depuis longtemps sur l'histoire de Saint-Boniface. Le choix du vocable de Saint-Boniface, par exemple, n'eut rien à faire avec les Meurons catholiques et allemands qui se trouvaient là (p. 69, note 57). L'étude démontre clairement que Provencher n'a pas fondé le Collège de Saint- 
Boniface dès son arrivée en 1818 , en dépit de ce qu'en disent plusieurs auteurs et malgré l'inscription de cette date sur la plaque commémorative à l'entrée de cette institution (p. 66, note 62). La véritable raison qui a déterminé les frères des Écoles chrétiennes à abandonner la charge du Collège est étudiée à la page 217 .

Pour ce qui est de la présentation du texte, beaucoup de renseignements biographiques incorporés dans les renvois pourraient être réduits considérablement sans nuire à leur valeur. Un grand nombre de citations ne font pas corps avec le texte faute de charnières qui établiraient la transition et offriraient un contexte approprié entre le texte et la citation. On doit aussi se méfier du mode de conversion suggéré pour exprimer la livre sterling en dollars. De multiplier celle-là par cinq répond peut-être aux exigences de la quantification mais le résultat fait abstraction du pouvoir d'achat de la dite monnaie. En dernière analyse si, comme on l'affirme dans la conclusion, c'est l'Église qui dirige les affaires et les écoles avant et après 1870 , et si le premier gouvernement municipal n'entre en vigueur qu'en 1880, l'histoire de Saint-Boniface mérite-t-elle d'être publiée en deux volumes? Peut-être eût-il été préférable de faire un résumé de ce premier volume, surtout des faits historiques assez bien connus, et de l'incorporer au deuxième tome qui aura pour thème le développement de Saint-Boniface comme centre urbain. Avant de conclure définitivement sur ce point, nous attendons la publication du second tome. 